\title{
La responsabilidad civil por daños causados por productos defectuosos. Retos y realidades en México
}

\section{Georgina Alicia Flores Madrigal}

Universidad Nacional Autónoma de México

\section{RESUMEN}

La protección de la integridad del consumidor constituye una prioridad, ante el riesgo de sufrir un daño inherente a la introducción de productos defectuosos en el mercado. La responsabilidad por productos defectuosos es un régimen de responsabilidad civil, que surge en virtud de la facultad con que cuenta todo consumidor ante un producto defectuoso de reclamar, al responsable, la reparación del daño que el producto ocasionó.

\section{PALABRAS CLAVE}

Integridad física, consumo, producto defectuoso, daño.

\section{ABSTRACT}

The protection of the integrity of the consumer is a priority, before the risk of harm inherent in the introduction of defective products in the market. The liability for defective products, it is a regime of civil liability that arises under the faculty with which all consumer account before a defective product, to reclaim, the responsible, repairing the damage done to the product caused.

\section{KEY WORDS}

Physical Integrity, consumption, defective product, damage. 


\section{Planteamiento}

¿Es suficiente la Ley Federal de Protección al Consumidor para regular la responsabilidad por el daño causado por productos defectuosos? Alternativas y propuestas.

\section{Un asunto complejo: la protección de los consumidores en sus relaciones de consumo. Derechos del consumidor}

La empresa Teavana México, comprometida con sus clientes en coordinación con la Procuraduría Federal del Consumidor, ha puesto en marcha una campaña de retiro voluntario de un accesorio: los tumblers de vidrio para té, unos contenedores a manera de termos, con doble pared de vidrio, que se ofrecieron en diferentes presentaciones. El retiro obedece al posible riesgo que podría presentar el producto: por su uso constante podría perder su resistencia, lo cual provocaría que el vidrio se estrelle, causando posibles laceraciones o quemaduras.

Como esta alerta emitida por la Profeco ${ }^{1}$ hay muchas más ${ }^{2}$ y son emitidas por dicha autoridad, cuando la Subprocuraduría de Verificación, Cofepris $^{3}$ o Senasica ${ }^{4}$, analizan un producto y determinan que no se puede vender porque pone en riesgo la vida, la integridad física y la salud de las personas, derechos todos consustanciales del ser humano que se tiene el deber de proteger, ya que los consumidores deben estar a salvo de los riesgos para su salud y su seguridad, que vienen de la mano del desarrollo económico.

La empresa Emerson Process Management, S. A. de C. V., comprometida con sus clientes y en coordinación con la Procuraduría Federal del Consumidor, ha puesto en marcha una campaña de retiro voluntario de las válvulas de alivio de presión Fisher de tres pulgadas, modelos H732 y $\mathrm{H} 832$, utilizados en la industria del transporte. El retiro obedece a lo siguiente: pudiera afectar la seguridad de los vehículos automotores cuando son conducidos en determinadas condiciones extremas. El vástago de la válvula de alivio puede fracturarse y causar que la porción superior del vástago se separe de la válvula y sea eyectado del tanque. Lo anterior puede resultar en la liberación descontrolada de gas presurizado a la atmósfera, que podría causar peligro en el camino, lesiones o incendios. Asimismo, la porción eyectada de la válvula podría impactar en otro vehículo y ocasionar lesiones personales o una colisión vehicular.

1 Profeco son las siglas de la Procuraduría Federal del Consumidor.

2 Trece alertas en lo que va del año. Ver http://www.profeco.gob.mx.

3 Comisión Federal para la Protección contra Riesgos Sanitarios.

4 Servicio Nacional de Sanidad, Inocuidad y Calidad Agroalimentaria. 
Toda la existencia del hombre se halla gobernada por la regla que ordena no causar daño a los demás. Sin embargo, son constantes las situaciones que nos ponen frente a circunstancias que causan daño. «El camino recorrido, desde la venerable máxima alterum non laedere, hasta las modernas tendencias doctrinales y legales, desengañadas del criterio de que solo la culpa del causante del daño justifica la responsabilidad civil, parecen querer retribuir a la vida, actualmente asediada por los riesgos, con la fórmula jurídica de acuerdo con la cual existe la obligación de indemnizar los daños que se ocasionen aunque no sean fruto del descuido o de la impericia de quien debe responder» ${ }^{5}$.

La sociedad de consumo alienta la elaboración de productos en masa o en serie. El consumidor de productos industrializados se encuentra en riesgo de sufrir un daño, aun sin negligencia, algo inherente a la introducción de productos defectuosos en el mercado y que puedan afectar su integridad, por lo que se constituye en una prioridad su seguridad dentro de la relación de consumo. Muestra de ello son las directrices para la protección del consumidor de la Organización de las Naciones Unidas ${ }^{6}$.

El derecho a la protección de la vida, la salud y la seguridad significa que los consumidores deben estar a salvo de los riesgos para su salud y su seguridad ${ }^{7}$.

La $\mathrm{LFPC}^{8}$ lo reconoce como principio básico en las relaciones de consumo (artículo 1): cuando se trate de productos o servicios que, de conformidad con las disposiciones aplicables, se consideren potencialmente peligrosos para el consumidor o lesivos para el medio ambiente, o cuando sea previsible su peligrosidad. El proveedor deberá incluir un instructivo que advierta sobre sus características nocivas y explique con claridad el uso o destino recomendado y los posibles efectos de su uso, aplicación o destino fuera de los lineamientos recomendados. El proveedor responderá de los daños y perjuicios que cause al consumidor la violación de esta disposición, sin perjuicio de lo dispuesto en el artículo 92 de esta ley (artículo 41).

Se considerarán casos particularmente graves (artículo 128): cuando la infracción de que se trate pudiera poner en peligro la vida, la salud o la seguridad de un grupo de consumidores.

\footnotetext{
5 Ángel Yagüez 1978: 7.

6 En su versión ampliada de 1999. Naciones Unidas: 2003.

7 Son documentos especializados la Directiva 85/374/CEE del Consejo, del 25 de julio de 1985, relativa a la aproximación de las disposiciones legales, reglamentarias y administrativas de los Estados miembros en materia de responsabilidad por los daños causados por productos defectuosos, y la resolución sobre indemnizaciones a consumidores del 25 de junio de 1987.

8 Así se hará referencia a la Ley Federal de Protección al Consumidor en México.
} 
Corresponde a la Secretaría de Economía expedir las normas oficiales mexicanas previstas por la ley, y a la Profeco, vigilar que se cumpla con lo dispuesto en la propia ley y sancionar su incumplimiento. Además, como autoridad administrativa, aplicará medidas precautorias cuando se afecte o se pueda afectar la vida, la salud, la seguridad o la economía de una colectividad de consumidores. Destacan (artículo 25):

a. Inmovilización de envases, bienes, productos y transportes.

b. El aseguramiento de bienes o productos en términos de lo dispuesto por el artículo 98 de esta ley.

c. La suspensión de la comercialización de bienes, productos o servicios.

d. Ordenar el retiro de bienes o productos del mercado, cuando se haya determinado fehacientemente por la autoridad competente que ponen en riesgo la vida o la salud de los consumidores.

e. La colocación de sellos e información de advertencia.

La posibilidad de compensación efectiva al consumidor se traduce en el derecho a exigir la reparación del daño, por la puesta en circulación de productos defectuosos. La LFPC también lo reconoce como principio básico en las relaciones de consumo (artículo 1) como la efectiva prevención y reparación de daños patrimoniales y morales, individuales o colectivos, aun cuando no sea específicamente en materia de productos peligrosos.

\section{El consumidor y el proveedor}

Los proveedores de bienes o servicios incurren en responsabilidad administrativa por los actos propios que atenten contra los derechos del consumidor y por los de sus colaboradores, subordinados y toda clase de vigilantes, guardias o personal auxiliar que les presten sus servicios, independientemente de la responsabilidad personal en que incurra el infractor (artículo 9).

¿Quién es considerado proveedor? La LFPC establece que es la persona que habitualmente ofrece, distribuye, vende, arrienda o concede el uso o disfrute de productos. Al leerse esto se piensa: ¿y los demás sujetos de la relación de consumo? La misma ley responde, pero no en el sentido esperado. La reclamación podrá presentarse indistintamente al vendedor, al fabricante 9 o al importador, a elección del consumidor, dentro de los dos meses siguientes a la fecha en que se haya recibido el producto, siempre que no se hubiese alterado por culpa del consumidor. El proveedor deberá satisfacer la reclamación en un plazo que no excederá de quince

9 Gómez Granillo 1995: 57. «Producir es asignar nueva forma a la materia, transformar lo que ya existe». 
días contados a partir de dicha reclamación. El vendedor, fabricante o importador podrá negarse a satisfacer la reclamación si esta es extemporánea, cuando el producto haya sido usado en condiciones distintas a las recomendadas o propias de su naturaleza o destino, o si ha sufrido un deterioro esencial, irreparable y grave por causas imputables al consumidor (artículo 93).

De lo anterior, se desprenden dos posibilidades:

La primera: no se considera proveedor al fabricante y no importa que se le haga una reclamación, pues él no es sujeto responsable de acuerdo con esta ley: solo es responsable quien produce o elabora productos.

La segunda: ¿acaso se considera que el proveedor es aquel que ofrece el producto y, por lo tanto, sujeto de la ley?

La jurisprudencia emitida por el Cuarto Tribunal Colegiado en materia civil del primer circuito en México ${ }^{10}$ intenta abordar la cuestión, aunque sin éxito, los actos jurídicos celebrados entre comerciantes o industriales o de unos con otros, en los cuales no se dé una relación de proveedor a consumidor, o no se encuentran regulados por la Ley Federal de Protección al Consumidor. En consecuencia, no quedan sujetos a ella los actos en los que las partes carezcan de tales cualidades. Se entiende por proveedor a los comerciantes, industriales, prestadores de servicios, así como las empresas de participación estatal, los organismos descentralizados y los órganos del Estado, en tanto desarrollen actividades de producción, distribución de bienes y prestación de servicios a consumidores, y por consumidor a quien contrata, para su utilización, la adquisición, uso o disfrute de bienes o la prestación de servicios, de acuerdo con las definiciones contenidas en los artículos 2 y 3 de dicha ley.

Parece que la jurisprudencia considera la segunda de las posibilidades. Aunque si esto es así, ¿por qué no hablar de productor, por qué usar el término proveedor?

En su exposición de motivos, la Ley Federal de Protección al Consumidor explica que recoge preceptos dispersos en la legislación civil y mercantil, buscando moderar los principios de igualdad entre las partes, de libertad de contratación y de autonomía de la voluntad, dándoles coherencia y unidad y elevándolos a la categoría de normas de derecho social, con el propósito fundamental de igualar a quienes en la vida económica son desiguales, como lo son, por una parte, el proveedor y, por la otra, el consumidor; tutela los intereses de este, al considerarlo como parte débil frente al proveedor. En tal virtud, dicho ordenamiento crea un régimen 
jurídico singular y contiene disposiciones que constituyen excepciones a las reglas generales establecidas en la legislación civil y mercantil, de suerte que debe ser interpretado restrictivamente, por lo que no puede ser aplicado a caso alguno que no esté expresamente especificado en el referido régimen.

Resulta claro que la presente ley no puede aplicarse a la materia que nos ocupa y habrá de observarse el resto del ordenamiento legal para atender las cuestiones relativas a la responsabilidad civil por daños causados por productos defectuosos.

Ese es el panorama nacional, mientras que en otras latitudes se han sumado esfuerzos, con el propósito de lograr consensos, y poner fin a las disparidades, respecto de un problema compartido, fruto de la actividad comercial, consolidando la postura en la que los productores serán responsables de los daños causados por los defectos de los productos que fabriquen o importen. De tal suerte que será productor, el fabricante o importador en la Unión Europea de:

a. Un producto terminado.

b. Cualquier elemento integrado en un producto terminado.

c. Una materia prima.

Se trata de un principio adoptado por los países miembros, como es el caso de España, en el Real Decreto Legislativo 1/2007, del 16 de noviembre, por el que se aprueba el texto refundido de la Ley General para la Defensa de los Consumidores y Usuarios y otras leyes complementarias (Libro tercero. Responsabilidad civil por bienes o servicios defectuosos).

\section{El producto defectuoso}

La LFPC no menciona qué entiende por producto, mucho menos cuando este es considerado peligroso. Únicamente establece, dentro del derecho del consumidor, a ser informado y conocer sobre los riesgos que representen.

«Producto: es el resultado material o intangible de la actividad humana destinado al consumo masivo» ${ }^{11}$. Y es, en principio, el objeto en el Ilamado derecho de consumo, entendido como cualquier bien mueble apto para el uso, y además que reúna las condiciones de seguridad a que todo consumidor tiene derecho.

Se considera que un producto es seguro cuando, utilizado en condiciones normales (consumidor racional) o razonablemente previsibles,

11 Rocha Díaz 1981: 383 
no presente riesgo alguno o presente riesgos mínimos (alcanzar un nivel adecuado de protección de la salud y seguridad de los consumidores) compatibles con el uso del producto (control de calidad). Por lo que se refiere a la aptitud para su uso, baste recordar que los vicios ocultos de la cosa que se enajena da lugar a la rescisión del contrato o a la reducción del precio, cuya elección corresponde al comprador.

Es la falta de seguridad lo que aquí preocupa y ocupa. Hay quien dice: por novedoso ${ }^{12}$, aunque yo creo que preocupa, debido a los riesgos de introducir productos defectuosos en el mercado de consumo.

Por lo tanto, un producto se considera defectuoso ${ }^{13}$ :

- Cuando no ofrece la seguridad a la que una persona tiene legítimamente derecho, teniendo en cuenta todas las circunstancias, incluso:

a. La presentación del producto (envase, instrucciones de ensamble, instalación y mantenimiento, etiquetado, instrucciones de uso).

b. El uso que razonablemente pudiera esperarse del producto (condiciones normales de uso). Por lo que se refiere a la aptitud para su uso, baste recordar que los vicios ocultos de la cosa que se enajena da lugar a la rescisión del contrato o a la reducción del precio, cuya elección corresponde al comprador.

c. El momento en que el producto se puso en circulación.

En todo caso, un producto es defectuoso si no ofrece la seguridad normalmente ofrecida por los demás ejemplares de la misma serie. Un producto no se considerará defectuoso por la única razón de que, posteriormente, se haya puesto en circulación un producto más perfeccionado.

En el Real Decreto Legislativo 1/2007, se observa lo establecido en las líneas precedentes, pues los miembros de la Comunidad Europea decidieron trabajar para unificar criterios y lograr avances. Resulta muy útil la subdivisión de los defectos en los productos:

- Defectos de fabricación: obedecen a causas dentro del proceso de producción y afectan a ejemplares pertenecientes de una misma serie, como es el caso de los vehículos y las alertas de las empresas automotrices.

\footnotetext{
12 Por lo novedoso del tema, las cursivas son nuestras.

13 Directiva 85/374/CEE del Consejo, del 25 de julio de 1985, relativa a la aproximación de las disposiciones legales, reglamentarias y administrativas de los Estados miembros en materia de responsabilidad por los daños causados por productos defectuosos (artículo 6). Real Decreto Legislativo 1/2007, del 16 de noviembre, por el que se aprueba el texto refundido de la Ley General para la Defensa de los Consumidores y Usuarios y otras leyes complementarias (artículo 137).
} 
- Defectos de proyecto o de diseño: son consecuencia de los errores en la adopción de los planes técnicos previos a la fabricación, elección de un material equivocado o deficiente fabricación del producto.

- Defectos de información: se presentan cuando el fabricante no comunica debidamente al público los peligros que el producto o las circunstancias especiales en las que el producto puede resultar peligroso.

La seguridad del producto debe ser prevista considerando dos aspectos:

- El deber de cuidado por parte del productor: la prohibición del empresario, entendido como proveedor, de introducir al mercado un producto a sabiendas del riesgo que atenta la seguridad de los consumidores. Sí se encuentra contenido en la Ley Federal de Protección al consumidor al referirse a los derechos de los consumidores.

- El deber de información por parte del productor: se han preocupado en tiempos recientes de atender el deber de informar, lo cual es importantísimo. Pero, claro, el deber de cuidado, que es materia del presente análisis, no puede esperar a ser atendido a la brevedad, ya que nos está alcanzando el defecto y está poniendo en peligro a grupos de consumidores cada vez más grandes, y ese consumidor afectado puedes ser tú.

Reitero, la LFPC no aborda tales cuestiones. Por lo tanto, es momento de proponer alternativas, a fin de atender las cuestiones que versan sobre la responsabilidad por las cuestiones extrínsecas del producto.

\section{Necesidad de abordar el problema desde la óptica de la responsabilidad civil}

Todo perjudicado tiene derecho a ser indemnizado por los daños o perjuicios causados por los bienes o servicios. Las acciones reconocidas en la Ley Federal de Protección al Consumidor no afectan a otros derechos que el perjudicado pueda tener a ser indemnizado por daños y perjuicios, incluidos los morales, como consecuencia de la responsabilidad contractual, fundada en la falta de conformidad de los bienes o servicios o en cualquier otra causa de incumplimiento o cumplimiento defectuoso del contrato, o de la responsabilidad extracontractual a que hubiere lugar.

\section{La responsabilidad civil por productos defectuosos}

La responsabilidad por productos defectuosos es un régimen de responsabilidad civil que surge en virtud de la facultad con que cuenta todo consumidor, ante un producto defectuoso, de reclamar, al fabricante o al distribuidor, la reparación del daño que el producto ocasionó, generalmente daños corporales. Se beneficia de la inclusión de productos en el mercado $y$, por tanto, de que sea quien indemnice a las personas que 
sufran algún daño por causa de tal producto. Además, puede incorporar las cantidades pagadas por concepto de reparación del daño en los costos de producción y, de ese modo, reparte el precio en la sociedad que adquiere el producto. Así surge la objetivización de la responsabilidad civil o, en otras palabras, el riesgo como criterio de imputación, que, junto con los demás elementos, harán posible la procedencia de la reclamación que derive en la reparación del daño.

Efectivamente, la responsabilidad civil presenta elementos comunes que permiten estructurar su procedencia. Por un lado, el elemento sin el cual no podría hablarse de responsabilidad y que no es otro que el daño. Para el caso que se comenta, es el efecto lesivo a la vida, salud o integridad de la persona, los daños corporales. Por otro lado, existe la conducta, consistente en una acción $u$ omisión, que en materia de responsabilidad por daños por productos defectuosos recaerá precisamente en el producto peligroso y su introducción en la relación de consumo. Asimismo, está la relación de causalidad, esto es, la conexión de causa a efecto que debe existir entre el comportamiento del responsable, o bien la conducta de una persona respecto de la que se tiene el deber de responder, y el resultado dañoso que se debe reparar. Finalmente, quizá después del daño el elemento más importante, el criterio de imputación, lo que significa cuestionarse: ¿por qué motivo está obligado a reparar el daño quien lo ha causado?

En principio, puede decirse que el autor del daño responde porque este se ha producido por su culpa. Esto quiere decir que está obligado a responder quien ha tenido un actuar imprudente $y$, a contrario sensu, que no responderá quien se comporte con la diligencia debida. Sin embargo, puede argumentarse que responde del daño quien de hecho lo causa, con independencia de que haya tenido la culpa o no de su producción. Debe responder del daño solo por haberlo causado, o por haber realizado una conducta apta para producir un riesgo.

Ambos criterios de imputación, culpa y riesgo, van a estar presentes en la materia que nos ocupa, pues ambos, alternativamente que no conjuntamente, nos pueden permitir conseguir la reparación del daño. El punto aquí será saber en qué casos utilizar uno u otro criterio, acompañado, claro está, de los demás elementos que hemos mencionado en los acápites precedentes.

Examinemos las posibilidades de exigir responsabilidad. Una de ellas la encontramos en el artículo 2104 de nuestro Código Civil ${ }^{14}$ :

14Código Civil Federal DOF 26 de mayo de 1928 y Código Civil para el Distrito Federal. GODF 25 de mayo de 2000. 
El que estuviere obligado a prestar un hecho y dejare de prestarlo o no lo prestare conforme a lo convenido, será responsable de los daños y perjuicios. [...] El que contraviene una obligación de no hacer pagará daños y perjuicios por el solo hecho de la contravención ${ }^{15}$.

Sin embargo, veremos que han aparecido una serie de regímenes especiales, Ley de Responsabilidad Civil para la Protección del Derecho a la vida Privada, el Honor y la propia imagen del Distrito Federal ${ }^{16}$, de responsabilidad civil extracontractual producidos todos ellos por vía legislativa, lo cual es posible debido a la cláusula general que contempla el artículo 1910 del Código Civil ${ }^{17}$ : «el que obrando ilícitamente o contra las buenas costumbres cause daño a otro está obligado a repararlo, a menos que demuestre que el daño se produjo como consecuencia de culpa o negligencia inexcusable de la víctima» ${ }^{18}$.

\subsection{Daño: el producto defectuoso quebranta la seguridad esperada. Un producto defectuoso propicia daños pecuniarios y no pecunia- rios, específicamente daños corporales ${ }^{19}$}

Los daños causados por productos defectuosos pueden agruparse en:

- Los daños causados al producto, que serán cubiertos por la garantía comercial.

- Los daños que causa el producto, en virtud del defecto que presenta y que afecta no al producto en sí, sino que afecta generalmente a las personas, y que se conoce como daño corporal, el cual emerge como un detrimento que repercute en la integridad física de las personas, y es circunstancia causante de lesiones o muerte; esta última es su manifestación más extrema.

\footnotetext{
15 La responsabilidad civil contractual corresponde a la obligación de reparar los daños y perjuicios que se causan por el incumplimiento de las obligaciones previamente contraídas, es decir, por la violación de un derecho que es correlativo de una obligación que puede ser de dar, hacer o no hacer, y cuyo deudor está individualmente identificado en el contrato del que se originan. Por su parte, la responsabilidad civil extracontractual no deriva del incumplimiento de un acuerdo de voluntades, sino de un hecho que violenta la ley en sentido amplio, es decir, de un derecho absoluto que es correlativo de un deber de abstención a cargo de un sujeto pasivo universal e indeterminado. Otra diferencia entre ambos regímenes es el paso de prescripción: para la primera será de 10 años y para la segunda, de dos años.

16GODF 19 de mayo de 2006.

17 Código Civil Federal y Código Civil para el Distrito Federal.

18 Una primera consideración es que el artículo 2104 regula la responsabilidad, la denominada contractual, mientras que el artículo 1910 hace referencia al régimen de la responsabilidad extracontractual. Pues bien, el régimen jurídico de la responsabilidad por daños causados por productos defectuosos es considerado como una zona mixta, en tanto puede tratarse de una responsabilidad contractual o extracontractual; en suma, habrá que centrarse en el criterio de imputación.
}

19 A mayor abundamiento: Flores Madrigal 2012: 27-74. 
Ante la existencia cada vez más reiterada del daño a la persona en sí misma, el panorama jurídico se encontraba dividido. Por una parte, las legislaciones que contemplaban dentro de sus ordenamientos disposiciones en donde se vislumbra la reparación del daño como cláusula general, abierta a la prueba de su existencia. Por otra parte, están las legislaciones que establecen categorías de daños y especificaciones puntuales dentro de estas últimas categorías, o bien legislaciones en las que, debido a ciertas limitaciones, precisen crear una categoría que reconozca el daño a la persona en sí misma.

Veamos un esbozo de la situación:

A. Países en los que, debido a la concepción amplia del daño en sus ordenamientos, no presentan dificultad para considerar que el daño corporal sí es un daño indemnizable, sin verse en la necesidad de adecuar disposición alguna. Tal es el caso de Chile, Perú, Argentina, Costa Rica, Puerto Rico, República Dominicana, México, España, Francia y Portugal ${ }^{20}$.

El Código Civil Españo ${ }^{21}$ no añade ninguna particularidad respecto del daño para que sea resarcible al tenor del siguiente enunciado, por lo que permite considerar cualquier daño causado, en principio como reparable:

Artículo 1902. El que por acción u omisión causa daño a otro, interviniendo culpa o negligencia, está obligado a reparar el daño causado.

La alusión al daño que realiza el precepto 313 del Código Civil de Puerto Rico ${ }^{22}$ es en los siguientes términos:

El que por acción u omisión culpable o negligente causa daño a otro está obligado a reparar el daño causado.

La imprudencia contribuyente del perjudicado a la causación del daño no exime de responsabilidad, pero conlleva a la reducción de la indemnización en proporción exclusivamente a la contribución del perjudicado.

Confirma lo anterior, al señalar en el artículo 315:

Por regla general, todo daño causado por culpa o negligencia es indemnizable, siempre que exista una relación de causalidad adecuada entre el hecho y el daño producido.

20 Los países que se señalan son solo ejemplos que no obedecen más que a ese fin, a pesar de que tres de ellos sí nos parecían referencia obligada, Alemania, Francia e Italia, por el tratamiento que en sus legislaciones hacen del daño corporal.

21 A mayor abundamiento: Sierra Gil de la Cuesta 2006.

22 Conocido como el Código Civil de 1930. 
La referencia al daño que realiza la normativa sustantiva civil del Estado peruano se contiene en los artículos 1969, 1970 y 1985, que a la letra dicen:

Artículo 1969. Aquel que por dolo o culpa causa un daño a otro está obligado a indemnizarlo. El descargo por falta de dolo o culpa corresponde a su autor.

Artículo 1970. Aquel que mediante un bien riesgoso o peligroso, o por el ejercicio de una actividad riesgosa o peligrosa, causa un daño a otro está obligado a repararlo.

Artículo 1985. La indemnización comprende las consecuencias que deriven de la acción u omisión generadora del daño, incluyendo el lucro cesante, el daño a la persona y el daño moral, debiendo existir una relación de causalidad adecuada entre el hecho y el daño producido. El monto de la indemnización devenga intereses legales desde la fecha en que se produjo el daño.

Similar alusión a la cláusula general realiza Bolivia ${ }^{23}$ en su título VII, referido a los hechos ilícitos, al expresar en su artículo 984:

Quien, con un hecho doloso o culposo, ocasiona a alguien un daño injusto, queda obligado al resarcimiento.

Artículo 994. El perjudicado puede pedir, cuando sea posible, el resarcimiento del daño en especie.

I. En caso diverso el resarcimiento debe valorarse apreciando tanto la pérdida sufrida por la víctima como la falta de ganancia en cuanto sean consecuencia directa del hecho dañoso.

II. El daño moral debe ser resarcido solo en los casos previstos por la ley.

III. El juez puede disminuir equitativamente la cuantía del resarcimiento al fijarlo, considerando la situación patrimonial del responsable que no haya obrado con dolo.

En este mismo sentido se pronuncia el Código Civil de Costa Rica, debido a la generalidad de su enunciado 1045, que a la letra dice:

Artículo 1045. Todo aquel que por dolo, falta, negligencia o imprudencia causa a otro un daño está obligado a repararlo junto con los perjuicios.

Por lo que toca al Código Civil chileno ${ }^{24}$, se refiere al daño en su título XXXV en materia de Delitos y Cuasidelitos, al tenor de los siguientes artículos: 
Artículo 2314. El que ha cometido un delito o cuasidelito que ha inferido daño a otro es obligado a la indemnización.

Artículo 2329. Por regla general, todo daño que pueda imputarse a malicia o negligencia de otra persona debe ser reparado por esta.

El Código Civil de Argentina contiene dentro de sus disposiciones al artículo 1068, que a la letra dice:

Artículo 1068. Habrá daño siempre que se causare a otro algún perjuicio susceptible de apreciación pecuniaria, o directamente en las cosas de su dominio o posesión, o indirectamente por el mal hecho a su persona o a sus derechos o facultades.

El Código Civil de Portugal establece en materia de responsabilidad civil un principio general:

Artículo 483. Aquel que con dolo o mera culpa viola ilícitamente el derecho de otro o cualquier disposición legal destinada a proteger intereses ajenos queda obligado a indemnizar a la víctima por los daños resultantes de la violación.

Solo existe obligación de indemnizar independientemente de culpa en los casos especificados en la ley.

El caso de Francia es especial ${ }^{25}$, pero lo incluimos en el presente apartado porque el artículo 1382 es una disposición general, abierta, a la prueba de la existencia del daño. Sin embargo, decimos que se trata de un caso especial porque es en este país donde se acuña el término daño corporal, vocablo que no se considera de modo unitario, sino mediante la referencia al daño fisiológico denominado también déficit fisiológico o funcional, y que consiste en la reducción permanente de las funciones físicas o psíquicas de la víctima.

Pero también ocurre que si las lesiones corporales no han dado lugar a secuelas y la víctima sana por completo, es decir, si no existe un daño fisiológico, la doctrina francesa considera igualmente que se tiene, en virtud de la lesión corporal, derecho a la indemnización, correspondiente al pretium doloris, por el dolor que ha sufrido la víctima debido a la lesión y por el eventual tratamiento médico a que se ha sometido.

Dicho lo anterior, volvemos al porqué de la ubicación del caso francés en este primer apartado.

Artículo 1382. Todo hecho del hombre que causa a otro un daño obliga a repararlo a aquel por culpa del cual ha sucedido (responsabilidad nacida de los hechos de los hombres). 
Artículo 1383. Cada uno es responsable del daño que ha causado no solo por su hecho, sino también por su negligencia o imprudencia (la responsabilidad nacida de la negligencia, identificada con la omisión).

El precepto citado establece una cláusula general: «el único hecho» que da lugar a la reparación es el que causa a otra un «daño»; no se hace ninguna distinción entre los diversos daños que pueden experimentarse; «esta disposición abarca en su vasta amplitud todos los géneros de daños» ${ }^{26}$, el desarrollo doctrinal y jurisprudencial que sobre el daño corporal se tiene, lleva a afirmar que «la antítesis tradicional se establece entre el daño material y el daño moral, a los que se añade una tercera categoría: el daño corporal»»27.

Por lo que respecta al Código Civil para el Distrito Federal, en México, se tiene una disposición general:

\section{Libro cuarto. De las obligaciones}

Capítulo V. De las obligaciones que nacen de los actos ilícitos

Artículo 1910. El que obrando ilícitamente ${ }^{28}$ o contra las buenas costumbres cause daño a otro está obligado a repararlo, a menos que demuestre que el daño se produjo como consecuencia de culpa o negligencia inexcusable de la víctima.

Detengámonos un momento para observar cómo en el caso de México. El capítulo comienza destacando que se refiere a las obligaciones que surgen como consecuencia de actos ilícitos. Esto llama la atención, sobre todo porque, como ya hemos dicho, a nuestro juicio la antijuridicidad no debe ser considerada como un elemento que configure o que dote de sentido al daño para efectos de su reparación.

Desde el momento en que la responsabilidad puede surgir como consecuencia de la realización de conductas lícitas, resulta innecesaria la referencia a la antijuridicidad como característica del daño indemnizable.

26 Mazeaud y Tunc 1961: 294.

27Carbonnier 1971: 65.

28 El ilícito como violación de un deber jurídico fundamental se encuentra expreso en los ordenamientos chileno, portugués, mexicano, alemán e italiano. En el Código Civil Federal Mexicano se estudia el hecho ilícito en dos partes. El capítulo comentado regula la responsabilidad extracontractual, en tanto no se precisa de la existencia de una relación jurídica previa, y comprende de los artículos 1910 al 1934. Por su parte, la responsabilidad contractual se encuentra regulada bajo el título cuarto, denominado «De los efectos de las obligaciones entre las partes. Incumplimiento de las obligaciones», que abarca del artículo 2104 al 2118. Ambos derivan de un hecho jurídico y de una conducta culpable, ya sea intencional o por negligencia. De esta forma, se puede definir al hecho ilícito como «toda conducta humana culpable». En este sentido, ver Gutiérrez y González 1999: 36-53. 
En este sentido, señalan ${ }^{29}$ Alterini, Ameal y López Cabana cómo se diluye el requisito de la antijuridicidad dentro de una moderna tendencia en la responsabilidad civil. De la misma forma, no se puede desconocer que hay casos en que el resarcimiento no responde a daño ilícito. Pero actualmente los juristas se encuentran afectados por el peso de la tradición, que los lleva necesariamente a relacionar correlativamente ambos conceptos. Sin embargo, poco a poco se están dando cuenta de que el resarcimiento aparece relacionado no solo con conductas ilícitas, sino también por actos lícitos ${ }^{30}$.

No obstante, el argumento que se esgrime para su inclusión es «que cuando aparece el calificativo de ilícito respecto de una conducta, esta resulta dañosa en contra de un particular y, por lo tanto, trae como consecuencia el nacimiento de la obligación a cargo del autor del acto de reparar el daño causado» ${ }^{31}$. Por ello, el ilícito civil juega un papel de vital importancia sobre los efectos de la voluntad de las partes, efectos que, o no se producen, o se producen y no son queridos, como sería: «la obligación de reparar el daño causado» ${ }^{32}$.

En el supuesto de la conducta dañosa, el dato decisivo para que nazca la obligación de reparar se presenta en la culpa, el dolo o el riesgo, en tanto criterios de imputación. En la búsqueda de la conducta jurídicamente reprobable, se puede observar que la conducta es ilícita en la medida en que constituye una violación del deber jurídico fundamental, que no es otro que la sujeción de los miembros de un grupo al orden jurídico. La conducta humana que el derecho reprueba es aquella que perturba el orden social y lo trastorna. El individuo que realiza la conducta ilícita no acata las bases de toda convivencia humana.

Sin embargo, este elemento no es necesariamente determinante para establecer un daño como indemnizable y lograr la reacción del orden jurídico que es, para el caso que nos ocupa, restitutoria o reparadora del daño causado a través de la responsabilidad civil.

29 Alterini, Ameal y López Cabana 1995: 150. En un fallo, la Corte Suprema de Justicia de la Nación tuvo oportunidad de pronunciarse al respecto al recordar que «el presupuesto básico para que se configure la responsabilidad del Estado por su accionar lícito consiste en que dicho obrar haya producido una lesión a una situación jurídicamente protegida» (del voto de los doctores Boggiano y Petracchi). C. S., 15 de agosto de 1995, Revestek S. A., Banco Central de la República Argentina y otros.

30 La doctrina alemana ha sido de gran influencia en códigos como el italiano. Precisamente ha puntualizado que «puede hablarse de antijuridicidad cuando se ha verificado un daño, esto es, el evento dañoso es por sí mismo suficiente para admitir la antijuridicidad. Sin embargo, en opiniones más recientes la doctrina considera que no todas las conductas que provocan daños son antijurídicas, sino que se necesita examinar caso por caso si la antijuridicidad subsiste». Ver Rozo Sordini 2002: 31.

31 Galindo Garfias 1981: 51.

32 Brebbia 2000: 39-41. 
B. Legislaciones que establecen dentro de sus disposiciones categorías de daños, dentro de las que especifican los daños sufridos por las personas en sí mismas. Ejemplo de esto es el caso de Alemania, que diferencia entre daño al cuerpo y daño a la salud.

Artículo. 1556. Quien está obligado a realizar una indemnización de daños ha de reponer el estado en que habría existido si la circunstancia que le hace responsable de la indemnización no hubiera ocurrido. Si la indemnización que se exige es por dañar a una persona o a una cosa, el acreedor puede exigir, en vez de la restitución, la suma de dinero necesaria para la restitución.

Por un daño que no sea un daño patrimonial, la indemnización en dinero solo puede solicitarse tal y como establece la ley.

Artículos 2314 y 2329 [Obligación de indemnizar por daños]

1. Quien, dolosa o negligentemente, de forma antijurídica, dañe la vida, el cuerpo, la salud, la libertad, la propiedad u otro derecho de otra persona, está obligada a indemnizarle cualquier daño causado por esto.

2. La misma obligación incumbe a aquel que infrinja una ley que tenga por objeto la protección de otro. Si, de acuerdo con las disposiciones de la ley, la infracción de esta es posible sin culpa, la obligación de indemnizar solo aparece en caso de culpa.

La doctrina alemana realiza una distinción respecto a los daños causados a las personas, que califica como «daños corporales y daños a la salud», de tal manera que el ordenamiento alemán —así lo entendemostipifica los daños que pueden ser indemnizables de manera expresa en su ordenamiento. Esta es la razón por la que la ubicamos en este segundo apartado y no en el primero. Además, al realizar esa distinción, se delimita el contenido de cada daño, de tal suerte que, mientras que la lesión corporal se define sobre la base de la lesión de la integridad corporal, la lesión a la salud se define sobre la base de una perturbación en el desarrollo del proceso de vida.

De igual forma, un rasgo más para considerar es el reconocimiento del resarcimiento de las consecuencias no pecuniarias en todo caso, se trate de daño corporal o daño a la salud. Al tenor del nuevo ${ }^{33}$ artículo 253, apartado 2, del Código Civil Alemán (Bürgerliches Gesetzbuch o $B G B)^{34}$ :

33 Reforma en 2002. El derecho alemán sufrió reformas significativas: una de ellas relativa al derecho de las obligaciones y otra, en cuanto al derecho de daños. La reforma entró en vigor el 1 de agosto de 2002. Es en este último ámbito que comentamos la reforma. Con repercusiones en materia de daño moral y la procedencia de su indemnización, en tanto establece que la «pérdida no pecuniaria» debe compensarse de manera adecuada en «cualquier caso», siempre que se deba a una lesión corporal, a daño a la salud o a la autodeterminación sexual. Es de resaltar la expresión, en todo caso, porque es el punto importante de la reforma, en 
Artículo 253 (1). Solo se puede solicitar indemnización dineraria por los daños no patrimoniales en los casos previstos por la ley.

(2). En el caso de la indemnización de los daños causados por una lesión corporal, a la salud, la libertad o la libertad sexual, también se puede exigir una indemnización equitativa en dinero por los daños causados que no sean patrimoniales.

Ahora bien, la diferenciación entre ambos supuestos en ocasiones pierde relevancia cuando constatamos que el tratamiento jurídico es el mismo. Así podemos verlo en la disposición 15 de la Ley Alemana de Responsabilidad Civil por Productos Defectuosos ${ }^{35}$, donde se recogen dichas distinciones.

\section{Responsabilidad por medicamento. Responsabilidad conforme a otras disposiciones}

En el caso de que alguien muera o sufra daños corporales o a su salud a consecuencia del uso de un medicamento destinado para uso humano, que sea suministrado al consumidor en el ámbito de aplicación de la Ley del Medicamento y que esté sujeto al procedimiento de autorización o esté exento del mismo mediante disposición reglamentaria, no son de aplicación las disposiciones de la Ley de la Responsabilidad Civil por Defecto de Producto.

Ley del Medicamento, artículos 84 y $84 a^{36}$ :

Artículo 84 (1). Si como consecuencia del uso de un determinado medicamento destinado al consumo humano, prescrito al consumidor en el ámbito de aplicación territorial de esta ley y que esté sometido a autorización sanitaria, o bien esté exento de la misma mediante disposición reglamentaria, se ha causado la muerte de una persona o bien ha sufrido lesiones corporales o a la salud significativas, el empresario farmacéutico, que ha introducido el medicamento en el mercado, de acuerdo con el ámbito de aplicación de esta ley, está obligado a indemnizar los daños causados. [...]

comparación con el tratamiento que antes de esta se hacía del daño moral. El artículo 253 BGB antes permitía el resarcimiento del daño no patrimonial «en los casos previstos por la ley», es decir, excluía de resarcimiento el daño moral que se padeciera en el ámbito de la responsabilidad objetiva y permitía su reparación en ciertos casos en el ámbito contractual, cuando el daño moral derivaba de lesiones corporales, daños a la salud, privación de la libertad. En este sentido, se manifiestan Ulrich 2010, y Lamarca i Marquès y Ramos González 2002. 34 En adelante se le llamará BGB.

35 Tras la aprobación de la Ley Alemana de Responsabilidad Civil por Productos Defectuosos de 15 de diciembre de 1989, la cuestión sobre la ley aplicable a la responsabilidad civil por los daños causados por medicamentos defectuosos fue resuelta, al establecer, en su numeral 15 , que no se aplicará la referida ley para los casos de medicamentos defectuosos que tienen cabida bajo el régimen de responsabilidad civil de la Ley Alemana del Medicamento.

36 Lamarca i Marquès y Ramos González 2002: 3. Los autores proporcionan artículos del BGB en texto original y su traducción, la cual hemos transcrito. 
Artículo 84a (1). En el caso de que se den circunstancias que fundamenten la consideración de que el medicamento ha causado el daño, el perjudicado puede exigir información del empresario farmacéutico, excepto cuando no sea necesario para determinar si procede una pretensión de indemnización según el artículo 84. La pretensión de información comprende los efectos terapéuticos, efectos secundarios e interacciones conocidos por el empresario farmacéutico, así como los casos sospechosos de efectos secundarios e interacciones que le sean conocidos, así como cualquier otra información relevante para determinar la responsabilidad de los daños causados. [...]

C. Otras legislaciones en las que, debido a las limitaciones impuestas al daño considerado indemnizable, se ven en la necesidad de crear una categoría de daño que reconozca el daño a la persona en sí misma

Tal es el caso de Italia ${ }^{37}$, que reconoce la indemnización de daños patrimoniales, vía el artículo 2043, pero restringe la indemnización de daños no patrimoniales a determinados supuestos permitidos por la ley, mediante el artículo 2059. Así, la realidad italiana presenta una situación particular, al encontrarse limitada la posibilidad de conceder una indemnización por lesión de daños no patrimoniales que no sean delitos.

Las disposiciones a las que hemos hecho alusión establecen en sus respectivos enunciados:

Artículo $2043^{38}$. Resarcimiento por hecho ilícito

Cualquier hecho doloso o culposo, que ocasiona a otro un daño injusto $^{39}$ obliga a aquel que ha cometido el hecho a resarcir el daño.

Artículo 205. El daño debe ser resarcido solo en los casos determinados por la ley ${ }^{40}$ y tales casos se reducen a aquellos provenientes de delitos.

37 Cannavò y Mastroroberto 2006: 491-504. Sin embargo, existe dentro de la doctrina italiana quienes opinan a diferencia de lo que sostenemos en el epígrafe $C$, que el ordenamiento italiano se funda sobre el principio de la atipicidad, porque el artículo 2043 expone que se trata de cualquier daño. Lo que hace que se configure, de acuerdo con dicha norma, una serie potencialmente infinita de hechos ilícitos. Ver la tesis de la atipicidad del ilícito en Rozo Sordini 2002: 37.

38 Corsaro 2000: 151. Respecto al artículo 2043, comenta que dicho precepto parece contener una toma de posición a favor de la teoría que ve en la antijuridicidad un modo de ser objetivo del evento (lesión del derecho ajeno) que no debe confundirse con la culpa. Esta norma general ha individualizado como elemento esencial del supuesto de hecho la objetiva lesión del derecho ajeno. En este sentido, no es posible negar que puede existir un hecho antijurídico aun cuando falte la capacidad del agente. Por lo tanto, hay que entender esto como rechazo por parte de la ley de la teoría de la ilicitud, comprendida como cualidad ligada a la capacidad del sujeto, y también como afirmación de la validez objetiva de la antijuridicidad, de su normatividad.

39 Injusticia o antijuridicidad como elementos necesarios del daño resarcible. Ver Rozo Sordini 2002: 30-42.

40 Ver Cian, Giorgio y Trabucchi Alberto (1981). Comentario breve al Código Civil. Padua. 
Estos preceptos hacen resaltar ciertas particularidades del derecho italiano. La primera de ellas, como hemos expresado, es la relativa al reconocimiento de la indemnización de los daños patrimoniales, vía el artículo 2043, y la procedencia de la indemnización, en ciertos casos, de las consecuencias no patrimoniales, mediante el artículo 2059. Ahora bien, la segunda particularidad es por lo que respecta al carácter «injusto del daño» del artículo 2043 (respecto de los daños patrimoniales).

El carácter injusto del daño hace referencia a un criterio selectivo de los intereses considerados dignos de tutela. Se parte del principio por virtud del cual la lesión de un derecho subjetivo absoluto obliga al autor de la lesión a resarcir las consecuencias negativas patrimoniales; se observa que, al igual que sucede en el derecho alemán, el texto italiano considera que solo los daños que constituyen lesión de derechos subjetivos de carácter absoluto podían ser considerados como daños resarcibles. Con la calificación del daño como injusto se pretende delimitar el ámbito de los daños resarcibles (se refiere a aquel daño que tiene por objeto un interés jurídicamente tutelado).

Dentro de este panorama se va moldeando una figura que tutela la lesión a la integridad física, los daños biológicos, que comprenden todo perjuicio a la persona que tenga una repercusión en su vida fisiológica, social, sus placeres, el daño estético, etcétera. Este daño se indemniza independientemente de la pérdida de capacidad de trabajo y de ingresos.

La tercera particularidad es respecto a naturaleza del daño a la integridad, pues, aun cuando para nosotros es un daño de naturaleza extrapatrimonial, para la doctrina italiana presenta naturaleza patrimonial, y esto es así porque se argumenta que en consideración a la integridad física se pueden alcanzar otros bienes provistos de utilidad económica, sin que por el hecho de provenir de bienes no patrimoniales - integridad física- se desvirtúe la naturaleza patrimonial de dichos bienes a alcanzar. En estos casos, se habla de la existencia de un daño patrimonial indirecto.

Cuando el daño afecta a la integridad del cuerpo humano, expresa Adriano de Cupis, hay que resarcir también el daño patrimonial que exigen las necesarias curas y de lo conveniente para reintegrarse en el bien personal de la propia salud ${ }^{41}$.

\subsection{Criterio de imputación}

En principio puede decirse que el autor del daño responde porque este se ha producido por su culpa. Esto quiere decir que está obligado a responder el fabricante, el proveedor, ya que en el proceso productivo se 
ha observado un actuar imprudente y falta al deber de vigilancia y control, como no comunicar al consumidor los peligros que conlleva un producto.

$$
\text { Culpa = por no atender el deber de cuidado. }
$$

Sin embargo, debido al tema tan complejo está lo relativo a la carga de la prueba, comprobación del actuar negligente, de ahí que aparezca el riesgo como criterio de imputación, que no se traduce en el riesgo de un daño per se, sino del riesgo de la actividad económica al poner en el mercado un producto defectuoso.

\section{Riesgo transformado en siniestro = precaución con los productos que pongas en circulación.}

Ambos criterios de imputación, culpa y riesgo, van a estar presentes, en la materia que nos ocupa, pues ambos, alternativamente que no conjuntamente, nos pueden permitir conseguir la reparación del daño. El punto aquí será saber en qué casos utilizar uno u otro criterio, acompañado, claro está, de los demás elementos que hemos mencionado en los acápites precedentes.

Artículo 1913. Cuando una persona hace uso de mecanismos, instrumentos, aparatos, vehículos automotores o sustancias peligrosas por sí mismos, por la velocidad que desarrollen, por su naturaleza explosiva e inflamable, por la energía de la corriente eléctrica que conduzcan o por otras causas análogas, está obligado a responder del daño que cause, aunque no obre ilícitamente, a no ser que demuestre que ese daño se produjo por culpa o negligencia inexcusable de la víctima.

\subsection{Nexo de causalidad. Sujetos de la relación de consumo}

La producción en masa de bienes de consumo y su destino a grandes sectores de la población ha producido daños que afectan a un gran número de personas, la diligencia debida, criterio de uso en la elaboración de productos se transforma, en un deber de vigilancia de la producción en masa o en serie (de ahí la importancia de las normas oficiales mexicanas). De manera que el productor ${ }^{42}$ debe evitar defectos dentro del ciclo productivo.

\footnotetext{
42Se entiende por productor a la persona que fabrica un producto acabado, que produce una materia prima o que fabrica una parte integrante, y a toda aquella persona que se presente como productor poniendo su nombre, marca o cualquier otro signo distintivo en el producto. Directiva 85/374/CEE del Consejo del 25 de julio de 1985, relativa a la aproximación de las disposiciones legales, reglamentarias y administrativas de los Estados miembros en materia de responsabilidad por los daños causados por productos defectuosos.
} 
Los primeros pasos en la materia han aparecido en Estados Unidos. $\mathrm{Y}$ aunque son muchos los casos que se pueden comentar, uno resulta ilustrativo: la empresa fabricante de un automóvil se defendía frente a la demanda del comprador de un vehículo que alegaba la existencia de un defecto de fabricación ${ }^{43}$. El tribunal admitió que el fabricante del producto tenía el deber de diligencia frente al público con independencia de los particulares vínculos obligatorios que le unan negocialmente a cualquier persona.

El productor pone en riesgo la seguridad del consumidor, el riesgo lo crea él y, por lo tanto, lo asume, en virtud de su intervención en el proceso de producción, como un responsable solidario respecto al consumidor y subsidiario hacia los demás, sin que sea necesario comprobar la culpa, pues en atención al deber de no causar daño y al deber de seguridad habrá que cuidar tal seguridad de los consumidores y no colocar en el mercado un producto defectuoso ${ }^{44}$.

\section{Corolario}

Queda como tarea pendiente en México el tratamiento específico de la responsabilidad civil por daños por productos defectuosos con todas las consideraciones expuestas, ya sea en una ley, como es el caso de otros países, o bien utilizando la legislación con que se cuenta, pero sin perder de vista que hay que fortalecer la utilización adecuada de los criterios de imputación, con la ayuda de lineamientos objetivos que faciliten a la autoridad no solo administrativa sino también judicial la atribución de la responsabilidad.

43 En los actuales procesos productivos la existencia de defectos en los productos escapa al vendedor. Parra Lucán 2002: 1180.

44 Food Drogs Administration (FDA) en Estados Unidos. Comisión Federal para la Protección contra los Riesgos Sanitarios (Cofepris), siempre que se trate de productos regulados por la Ley General de Salud. 


\section{REFERENCIAS BIBLIOGRÁFICAS}

ALTERINI, Atilio; AMEAL, Óscar, y LÓPEZ CABANA, Roberto (1995). Derecho de obligaciones civiles y comerciales. Buenos Aires: Abeledo Perrot.

ÁNGEL YAGÜEZ, Ricardo de (1978). Lecciones sobre responsabilidad civil. Bilbao: Publicaciones de la Universidad de Deusto.

BREBBIA, Roberto. H. (2000). «La responsabilidad extracontractual en el proyecto de unificación del derecho privado en América Latina». En Roma e América. Diritto Romano Comune. Rivista di diritto dell'integrazione e Unificacazione del Diritto in Europa e in America Latina, nro. 10.

CANNAVÒ, Giovanni y MASTROROBERTO, Luigi (2006). «Valoración y reparación del daño corporal en Italia». En Cesar Borobia Fernández (coordinador). Valoración del daño corporal. Barcelona: Masson.

CARBONNIER, Jean (1971). Derecho civil. Barcelona: Bosch.

CORSARO, Luigi (2000). «Culpa y responsabilidad civil: la evolución del sistema italiano». En Juan Antonio Moreno Martínez (coordinador). Perfiles de la responsabilidad civil en el nuevo milenio. Madrid: Dykinson.

CUPIS, Adriano de (1975). El daño. Teoría general de la responsabilidad civil. Barcelona: Bosch.

FLORES MADRIGAL, Georgina (2012). «La reparación de los daños causados a la vida e integridad corporal». En Revista de Derecho Privado, nro. 2.

GALINDO GARFIAS, Ignacio (1981). «El ilícito civil». En Estudios de derecho civil. México D. F.: Universidad Nacional Autónoma de México.

GÓMEZ GRANILLO, Moisés (1995). Breve historia de las doctrinas económicas. México D. F.: Esfinge.

GUTIÉRREZY GONZÁLEZ, Ernesto (1999). Personales teorías del deber jurídico y unitaria de la responsabilidad civil. México D. F.: Porrúa.

HUGUES-BEJUI, Hélène (2006). «Valoración y reparación del daño corporal en Francia». En Cesar Borobia Fernández (coordinador). Valoración del daño corporal. Barcelona: Masson.

LAMARCA I MARQUĖS, Albert (2001). «La modernización del derecho alemán de obligaciones: la reforma del BGB». En Indret, nro. 4.

LAMARCA I MARQUÈS, Albert y RAMOS GONZÁLEZ, Sonia (2002, julio). «Entra en vigor la segunda ley alemana de modificación del derecho de daños». En Working Paper, nro. 96.

MAZEAUD, Henri; MAZEAUD, León; TUNC, André, y ALCALÁ-ZAMORA Y CASTILLO, Luis (1961). Tratado teórico y práctico de la responsabilidad civil delictual y contractual. Buenos Aires: Ediciones Jurídicas Europa-América. 
NACIONES UNIDAS (2003). Directrices de las Naciones Unidas para la protección del consumidor. Nueva York: Naciones Unidas.

PARRA LUCÁN, María Ángeles (2001). «La responsabilidad civil por productos y servicios defectuosos. Responsabilidad civil del fabricante y de los profesionales». En Fernando Reglero Campos (coordinador). Tratado de responsabilidad civil. Navarra: Aranzadi.

ROCHA DÍAZ, Salvador (1981). «La protección jurídica del débil en el consumo. Responsabilidad civil por productos defectuosos». En Jorge A. Dávila Sánchez-Cordero (coordinador). La protección del consumidor. México D. F.: Nueva Imagen.

ROZO SORDINI, Paolo Emanuele (2002). El daño biológico. Bogotá: Universidad Externado de Colombia.

SIERRA GIL DE LA CUESTA, Ignacio (2006). Comentario al Código Civil. Barcelona: Bosch.

ULRICH, Magnus (2002). «La reforma del derecho alemán de daños». En InDret, nros. 2-3, Working Paper 127.

\section{Documentos:}

Directiva 85/374/CEE del Consejo, del 25 de julio de 1985, relativa a la aproximación de las disposiciones legales, reglamentarias y administrativas de los Estados miembros en materia de responsabilidad por los daños causados por productos defectuosos.

Código Civil Federal de México

Código Civil para el Distrito Federal de México

Ley Federal de Protección al Consumidor de México.

Real Decreto Legislativo1/2007, del 16 de noviembre, por el que se aprueba el texto refundido de la Ley General para la Defensa de los Consumidores y Usuarios y otras leyes complementarias. 